\title{
An Introduction to Dr. Nishimura Masanari's Research on the Lung Khe Citadel
}

\author{
Nishino Noriko \\ Foundation to Safeguard the Underground Cultural Heritage in Southeast Asia, \\ Japan \\ norikonishino@gmail.com
}

\begin{abstract}
This paper introduces Nishimura Masanari's research on the Lung Khe Citadel, which was built in the second century $\mathrm{CE}$ and continuously occupied until the end of the fifth or early sixth century. Nishimura explored four main topics. First, based on the largescale bronze workshop in the citadel, he argued that the casting of the bronze drum there had a political purpose. Second, he proved that the Lung Khe Citadel was Long Bien, not Luy Lau. Third, he discovered several types of artifacts, including a tableshaped stone mortar (pesani) and kendi that show cultural affinity with artifacts found in Tra Kieu and Oc Eo. Hence, the cross-regional Nanhai trade and political power at Lung Khe might have reciprocally stimulated each other. Finally, Nishimura advanced the far-reaching hypothesis that the prosperity of Chinese Buddhism might have stemmed from the Lung Khe area, on the basis of his study of roof tile ends with mask or lotus petal motifs.
\end{abstract}

\section{Keywords}

Buddhism - Champa - citadel - Lung Khe - Long Bien - Luy Lau - mold of bronze drum - roof tile - Si Nhiep

\section{Nishimura Masanari's Studies of Lung Khe}

From 1995 to 1997, Dr. Nishimura Masanari carried out a general survey in Bac Ninh Province, covering every district of the province (Fig. 1). In 1998, in his exploration of the Lung Khe Citadel, Dr. Nishimura found and identified the 


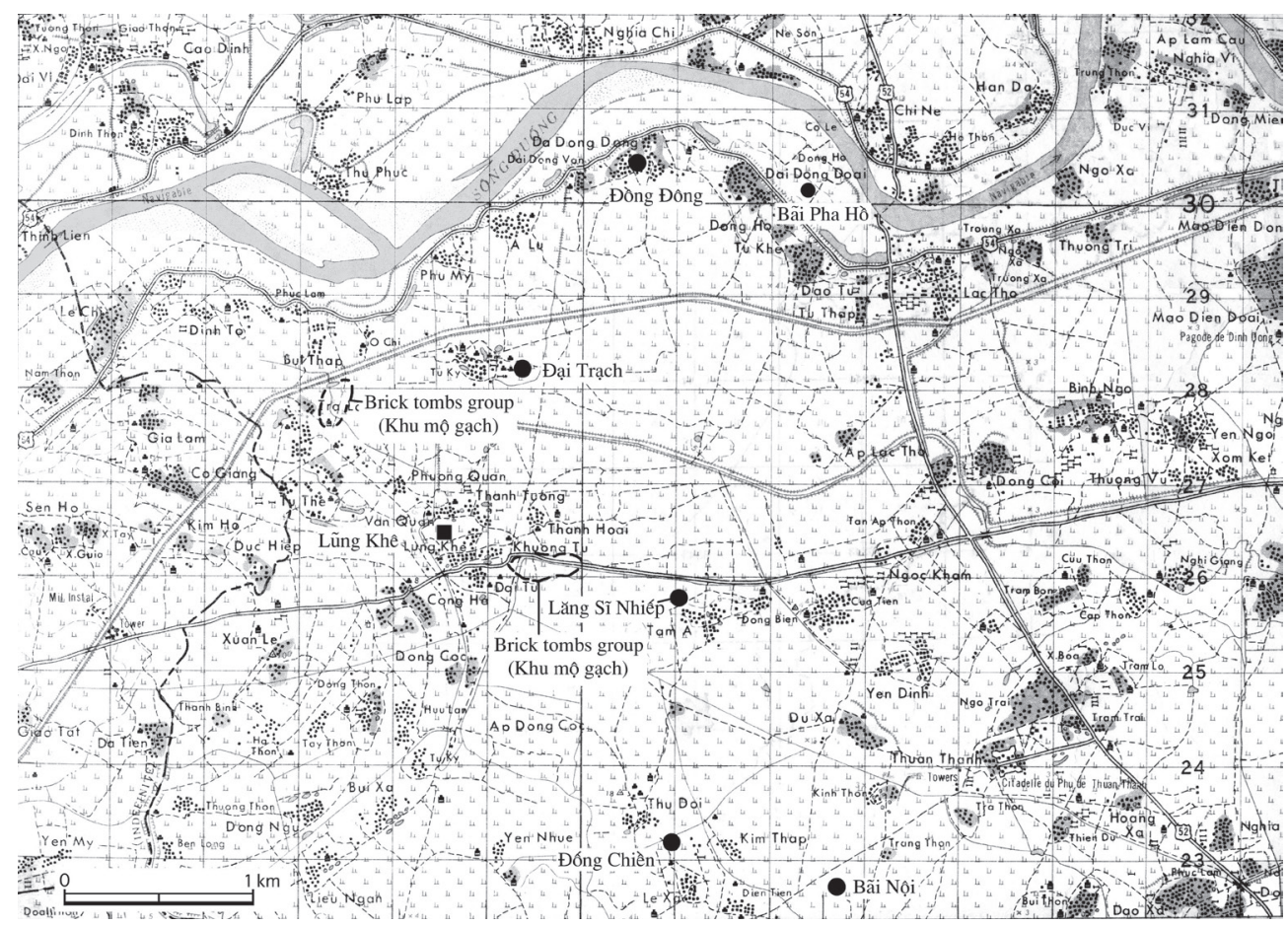

FIGURE 1 Lung Khe Citadel and its surroundings.

mold of a Heger type I bronze drum at the site, which had been destroyed by a brick factory. It was the first discovery of a Heger type I bronze drum mold. Immediately, he appealed to the Vietnamese scholars' society to take action to preserve the site. In the end, the brick factory was relocated and the site was protected. By this time, the discovery of the bronze drum mold had attracted the attention of Vietnamese scholars as well as the public.

The Lung Khe Citadel site is located on the natural levee of the old Dâu River, at Lung Khe Hamlet, Thanh Khuong Village, Thuan Thanh District, Bac Ninh Province. The citadel (Fig. 2) includes a large rectangular walled fort (north wall, $680 \mathrm{~m}$; south wall, $520 \mathrm{~m}$; east wall, $320 \mathrm{~m}$; and west wall, $328 \mathrm{~m}$ ).

Previous studies identified the Lung Khe Citadel as the central citadel of the Luy Lau District (贏㜢縣), which was established as the capital of the Giao Chi District (交趾郡) in the Western Han period and was also a former residence of Shi Nhiep (士謍), prefect of the Giao Chi. Recent studies will lead to a revised understanding of the citadel and its place in history.

Dr. Nishimura, Assistant Professor Pham Minh Huyen, and others excavated at the Lung Khe site in May 2001, and Dr. Nishimura also joined the excavation 


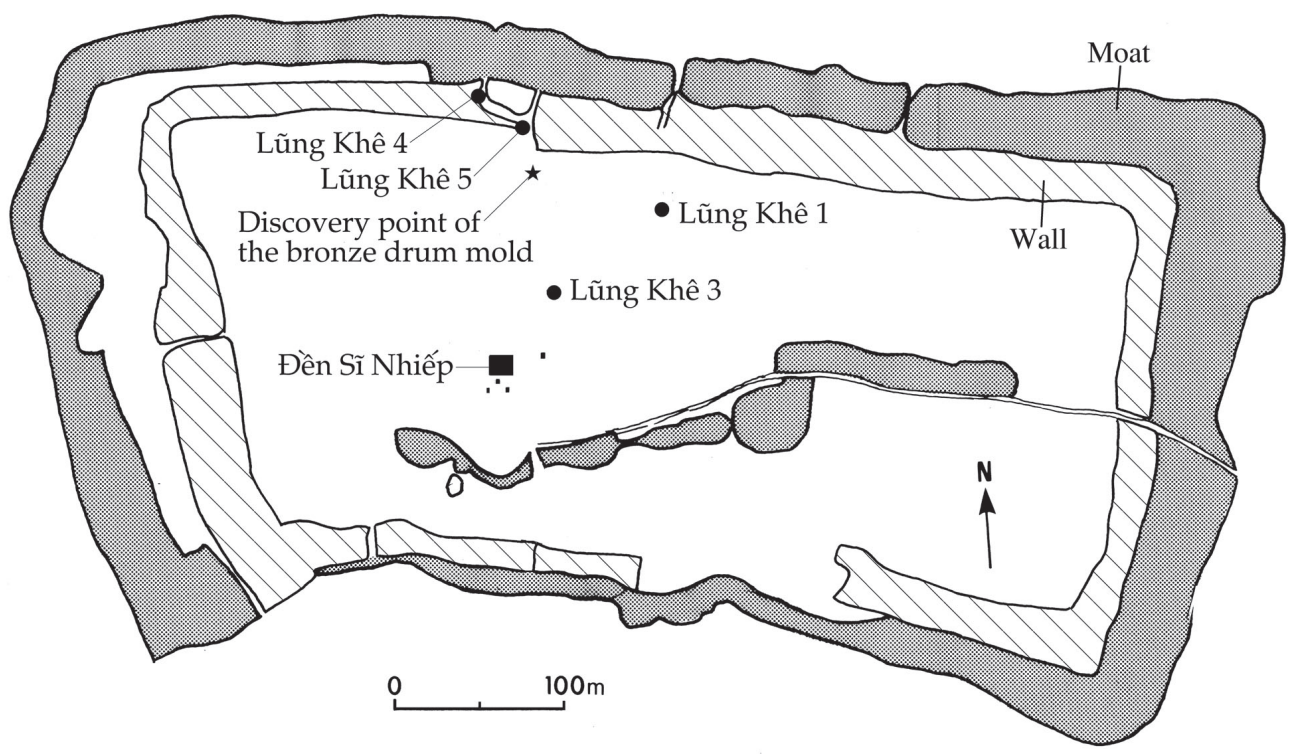

FIGURE 2 Plan of Lung Khe Citadel.

of the Lung Khe Citadel conducted by the Department of History, Hanoi National University. In his archaeological research, Dr. Nishimura always followed the principle, "Study first, theorize later." After studying the stratigraphy of the layers and their chronological sequence, he developed his theories. His studies of the Lung Khe Citadel focused on four main topics. The first topic is the large-scale bronze workshop that was identified inside the central part of the north wall. A mold fragment of the bronze drum found in this area indicates that it was part of the workshop where late Heger type I drums were cast.

Second, Dr. Nishimura examined the period of use of the Lung Khe Citadel site, studying artifacts and the internationalization that occurred during that period. Excavations and field research reveal that the citadel was built in the second century CE and continuously occupied till the end of the fifth or early sixth century. Although the majority of the artifacts were of Chinese origin, several types of artifacts, such as roof-tile ends, a table-shaped stone mortar (pesani), and kendi vessels, show cultural affinity with those found in Tra Kieu and Oc Eo, where early Southeast Asian states were formed.

Third, he pointed out that the Lung Khe Citadel was not the Luy Lau Citadel but the Long Bien Citadel. Among the early citadels or fort sites in the Red River Delta, Lung Khe was the largest after Co Loa (Fig. 3). The construction of Co Loa can be dated between the first century BCE and first century $\mathrm{CE}$, and after its construction it was apparently not used for a long time. On the other hand, 


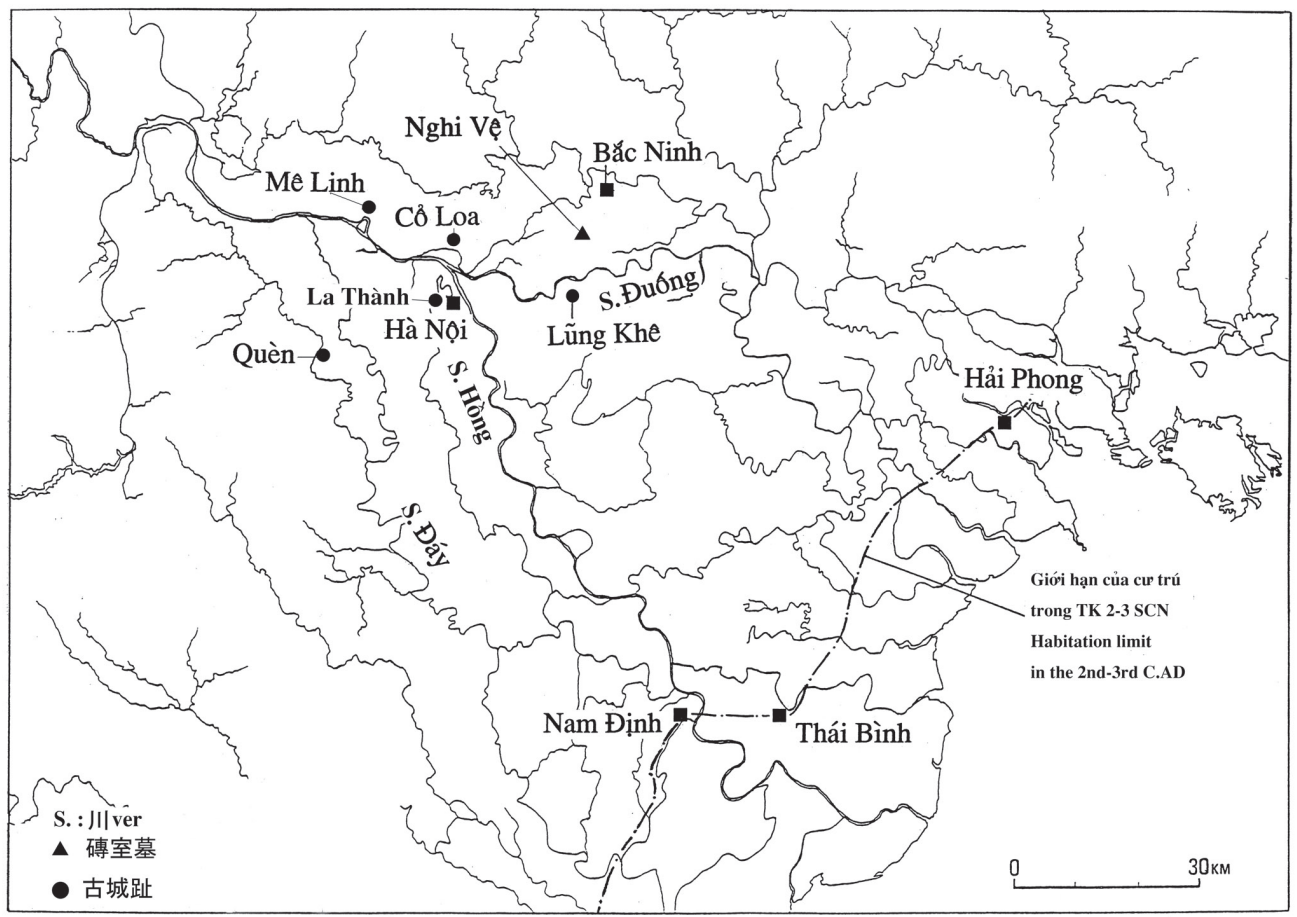

FIGURE 3 The citadels in the Red River Plain.

the scale, occupation period, and findings make Lung Khe a strong candidate for the central capital of the Red River Delta, which must have been Long Bien (龍編). While there are many historical or legendary relics of Si Nhiep around Lung Khe, no early document mentions relations between Si Nhiep and Luy Lau. The title of Long Bien Hau (龍編侯), which according to San Kuo Chih (三国志) was conferred on Si Nhiep as the lord of the district, provides supporting evidence for this hypothesis.

Finally, Dr. Nishimura advanced the far-reaching hypothesis that the prosperity of Chinese Buddhism might have stemmed from the Lung Khe area, based on the roof-tile ends with mask or lotus petal motifs. (Dr. Pham Le Huy discusses this topic from the viewpoint of historical studies in his article "A Reconsideration of the Leilou-Longbian Debate: A Continuation of Research by Nishimura Masanari" in this issue.) He also discussed the date of the beginning of Buddhism in Vietnam. (Dr. Le Thi Lien discusses this topic in her article "Lung Khe and the Cultural Relationship between Northern and Southern Vietnam" in this issue.) 
Dr. Nishimura analyzed the structure of the mound and citadel in comparison with other Vietnamese or South China citadels. The results of his analysis are summarized in his book Archaeology and Ancient History of Vietnam. ${ }^{1}$

\section{Dating the Use of the Citadel}

At the Lung Khe Citadel, artifacts predating the Dong Son period have been unearthed. The Dai Trach site, located $2 \mathrm{~km}$ north of Lung Khe Citadel, and the Tam A site, $2 \mathrm{~km}$ east of the citadel, also contained artifacts from the Dong Dau period to the Dong Son period. ${ }^{2}$ This means that the south bank of the Duong River had been settled as early as the Dong Dau and Dong Son periods. On top of the earlier layer of the Dong Son culture settlement, people possessing Chinese culture began to settle down.

Following a chronological study of the pottery, the artifacts from $\mathrm{LK}_{1}, \mathrm{LK}_{4}$, and $\mathrm{LK}_{5}$ were dated to the third quarter of the second century CE. ${ }^{3}$ The Lung Khe Citadel was built in the middle of the second century, and Madorolle's account of its founding follows the Taiping huanyu ji (太平環宇記), vol. $170 .{ }^{4}$ Zhou Chang (周敞) of the Han Dynasty probably moved the capital to Long Bien during 142-143 CE.

To determine when use of the Lung Khe Citadel ceased, it would help to know the date of the third period of the citadel. The upper layers (Layer 1 and

1 Nishimura Masanari, Archaeology and Ancient History of Vietnam (Betonamu no KokoKodaigaku) (Tokyo: Doseisha, 2011), 164-167.

2 Pham Minh Huyen and Nishimura Masanari, "Dieu tra khao co hoc hai huyen Thuan Thanh va Gia Luong tinh bac Ninh" (Survey in Two Districts, Thuan Thanh and Gia Luong in Bac Ninh Province), Nhung phat hien moi ve Khao co hoc nam 1997 (New Discoveries in Archaeology in 1997) (1998): 135-137; Pham Minh Huyen and Nishimura Masanari, "Bao cao khai quat di chi Dai Trach thang 11, nam 2004" (Report on the Dai Trach Site Excavation, November 2004), in Tu lieu vien khoa co hoc (Excavation Report for Institute of Archaeology) (2004); Pham Minh Huyen, "Nhan dien van hoa Dong Dau o di chi Dai Trach" (Perception of Dong Dau Culture at the Dai Trach Site), Khao Co Hoc (Archaeology) 1999, no. 4 (1999): 19-41; Nishimura Masanari, "Chronology of the Neolithic Age in the Southern Vietnam," Journal of Southeast Asian Archaeology 22 (2002): 25-58.

3 Nishimura Masanari, "Basic Data and Recognition about Pottery from the Latter half of 1st Century to 2nd Century in Red River Plain, Northern Vietnam," East-Asian Archaeological Forum 3 (Gongju-si: Chusei bunkazai kenkyuin, 2007), 57-101.

4 Claudius Madrolle, "Le Tonkin ancien. Lei-leou et les districts chinois de l'époque des Han. La population. Yue-chang," Bulletin de l'Ecole française d'Extrême-Orient 37, no. 1 (1937): 263-332. 
Layer 2) of the LK1 site provide a reference for the ending date of the site. Figure $4(8-12)$ shows five different bowls with glaze excavated at $\mathrm{LK}_{1}$ and $\mathrm{LK}_{3}$. There are lines below the mouth rim lines, the bottom is not curved, and graygreen glaze extends to the foot rim. The stacking technique of clods differs from that used during the former stage. Comparison of the glazed bowl with artifacts from Guangdong in southern China provides a good reference for the date. Artifacts found in the tombs were examined to determine when they were last used.

In bowls produced during the Nanchao period (420-598 CE) in China, a distinct base began to emerge. In shape, the bowl is higher than its width. This trend was also found in the bowls at the $\mathrm{LK}_{1}$ and $\mathrm{LK}_{3}$ sites. The bowls unearthed in the tomb in Guangdong Province 广東省元嘉十八 are not of the same height and shape of as those from LK1 and LK3. The shape and manufacturing techniques of the bases of vessels from the tomb of Jieyang Prefecture 楬陽県 (Guangdong) are very similar to the vessels from the Lung Khe Citadel. One of the three tombs excavated contained a brick dated to the fourth year of Daming (大明四年, $460 \mathrm{CE}$ ), and the pottery assemblage is the same as in the other two tombs, which are probably of similar date. ${ }^{5}$ The artifacts of the tomb in Yingde County 广東省英徳県石墩嶺 (Guangdong) and Tomb 16 in Shaoguan City (Guangdong) 6 are similar to those from the upper part of LK1 and $\mathrm{LK}_{3}$ in shape and in the placement of the glaze.

A celadon from the tombs of Chidong (赤東) in Guangdong (specifically Tomb 11), ${ }^{7}$ dated to the second half of the sixth century, has a greater height than width, different from the $\mathrm{LK}_{1}$ and $\mathrm{LK}_{3}$ types. The bowl from the Thuy dynasty $(581-618)$ is much higher than its width. The glaze does not cover the bottom of the bowl, and the mouth part has also become wider. ${ }^{8}$

Based on the above analysis, the artifacts of the upper layer of $\mathrm{LK}_{1}$ and $\mathrm{LK}_{3}$ are from the late fifth century to the beginning of the sixth century. They date no later than the first half of the sixth century, which indicates when the citadel was no longer used.

5 Guangdong Cultural Relics Management Committee, Shantou Department of Culture Affairs, and Jieyang Museum, "Excavation of East Jin, Southern Dynasty to Tang Graveyard at Jieyang, Guangdong," Kaogu 10 (1987): 895-903.

6 Yang Ho, "The Southern Dynasty Graveyard at Shaoguan City suburb, Guangdong," Kaoguxue Jikan (Archaeology Periodical) 3 (1983): 154-161.

7 Guandong Province Museum, "Excavation of Tang Dynasty Graveyard in Shixing County, Guangdong Province," Kaoguxue Jikan (Archaeology Periodical) 2 (1982): 113-133.

8 Peter Y. K. Lam, Archaeological Finds from the Jin to the Tang Periods in Guangdong (Hong Kong: Guangdong Provincial Museum and the Art Gallery, Chinese University of Hong Kong, 1986). 

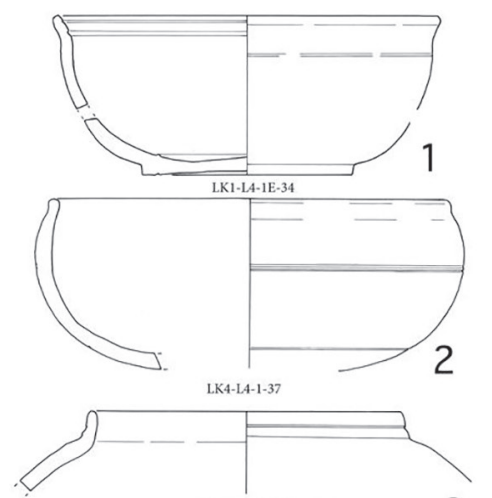

LK1-LA-1E+LBD10A-23 $\quad 3$
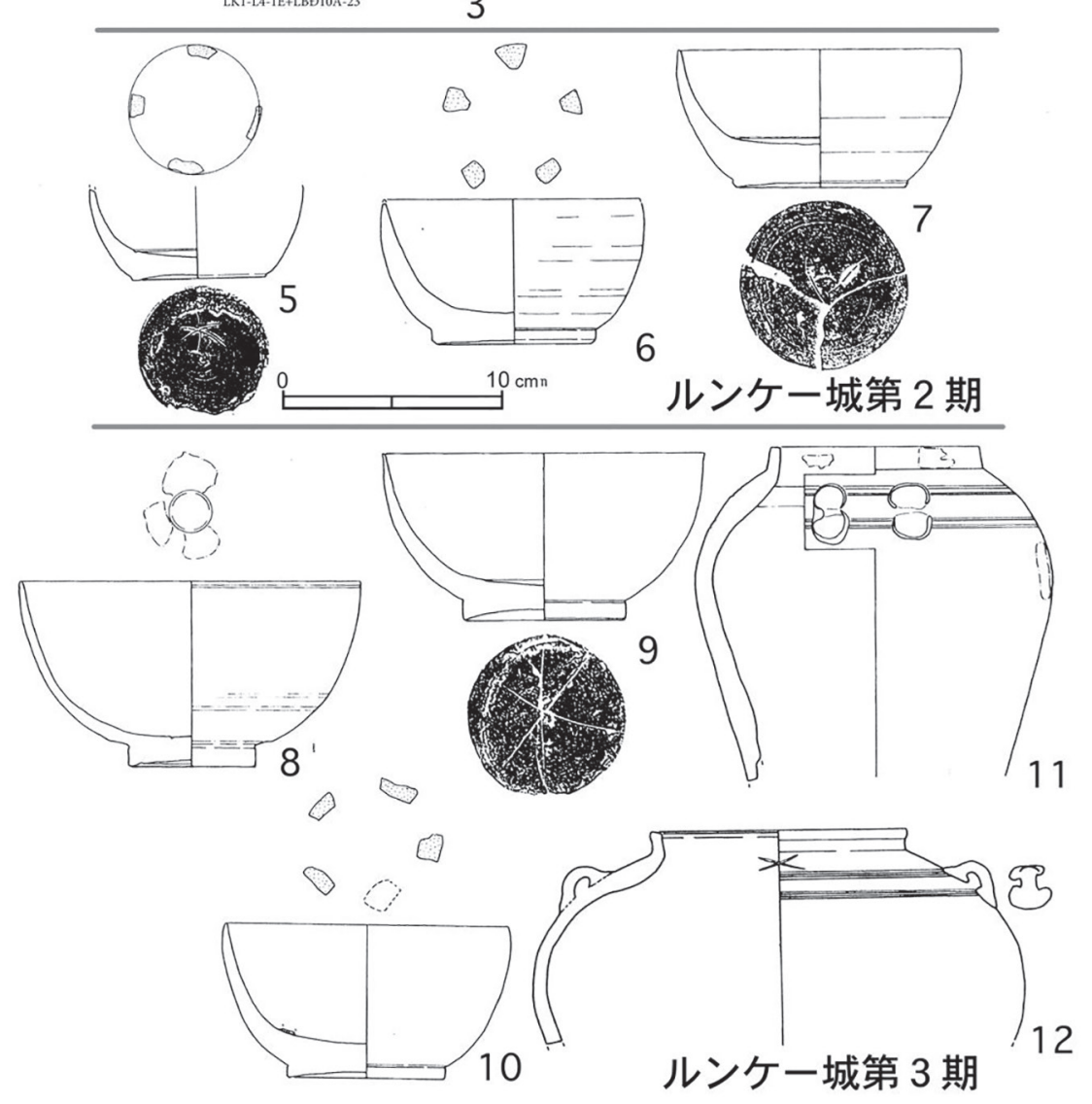

FIGURE 4 Representative types among the pottery excavated at the Lung Khe Citadel.

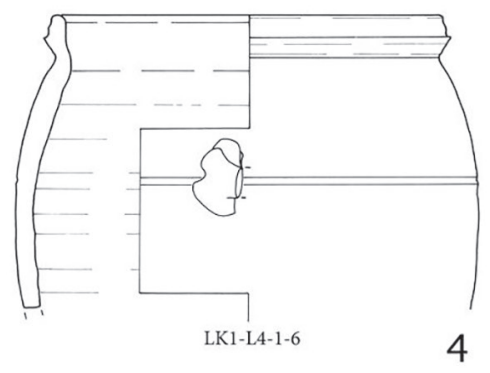

ルンケー城第1期 
Of course, the top layer includes artifacts from the Tang period to the present; it cannot be used to date the use of the citadel.

\section{International Artifacts}

The artifacts excavated at the Lung Khe site consist of pottery, bricks, and roof-tile ends, most of which were locally made. The manufacturing technique and the shape, however, originated from the Reinan (Lingnan 嶺南) area in southern China. In addition, artifacts of non-Chinese origin have also been discovered. The archaeological evidence provides clues to the nature of the governing authority at the Lung Khe Citadel. Dr. Nishimura mentioned several examples and their context.

Figure 5 (1-3) shows artifacts excavated in 1986 around the Si Nhiep Mausoleum in the middle part of the citadel. ${ }^{9}$ The eave-end roof-tile ends that are inscribed with the Chinese characters for wansui (万歳) and wei zhi sangong (位至三公) are typical of the Han-Three Kingdoms period. These rooftile ends clearly indicate that the person living there was a ruler of Chinese descent.

LK5-L6-29 (Fig. 5.4) is a very rare type of roof tile. The motif is a transformation of the cloud motif often seen on Chinese roof-tile ends. LK1-L4-2D Fig. 5.5) was excavated from the lowest layer of LK1. Another roof-tile end has a lotus panel decoration (Fig. 5.6).

LK1-L4-1E-31 (Fig. 5.7) shows face-mask tile ends, excavated with roof-tile ends decorated with the lotus panel. The surfaces of all tiles in Figure 5.2-4 show the cross-grain pattern of the wooden tool used for smoothing the joint when the ends of the tiles were connected. Examples of roof-tile ends with a face motif were also unearthed in the Tam Tho kiln ${ }^{10}$ and at Con Chan Tien in Thanh Hoa Province, Than Tra Kieu in Quang Nam Province (Fig. 6.4-5), ${ }^{11}$ the My Son site (the religious center of the Champa Kingdom), the Anh Thanh

$9 \quad$ Tong Trung Tin and Le Dinh Phung, "Bao cao nghien cuu khu di tich Luy Lau (Thuan Thanh-Ha Bac) nam 1986)" (Report for Luy Lau Site in Thuan Thanh Prefecture, Ha Bac Province in 1986), in Tu Lieu Khao co hoc (Report of Institute of Archeology) (Hanoi: Institute of Archaeology, 1987).

10 O. R. Jance, Archeological Research in Indo-China, vol. 1 (Cambridge, MA: Harvard University Press, 1947); idem, Archeological Research in Indo-China, vol. 2 (Cambridge, MA: Harvard University Press, 1951).

11 Yamagata Mariko, "Formation of Lin Yi: Derived from the Archaeological Materials of Chinese Origin found at Tra Kieu, Central Vietnam," Journal of Southeast Asian Archaeology 17 (1997): 167-184; Yamagata Mariko and Momoki Shiro, "Han and Six Dynasty 

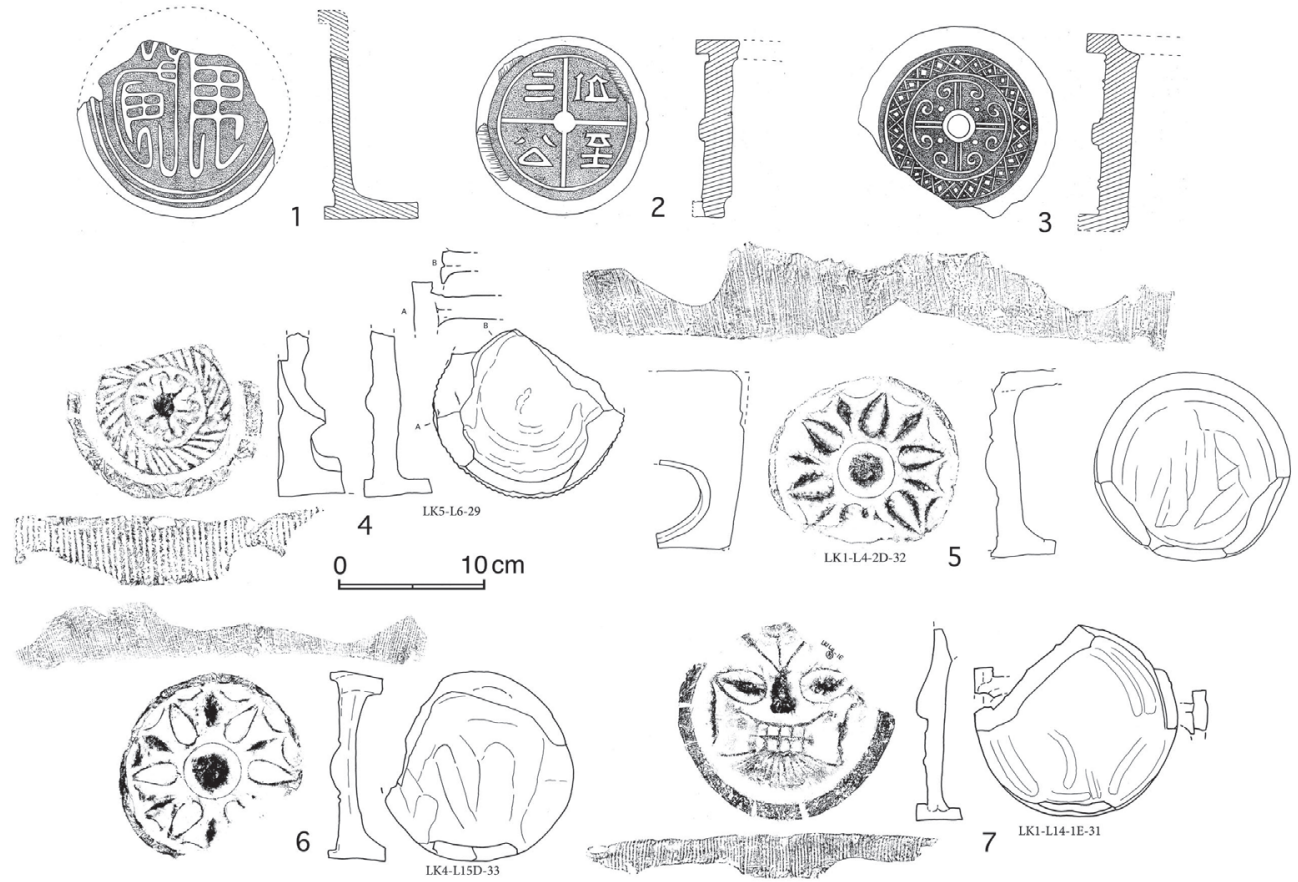

FIGURE 5 Tile ends unearthed in the Lung Khe Citadel.

Champa Citadel site in Binh Dinh Province, the citadel in Nanjing, China (Fig. 6.1-3), and elsewhere.

The tiles with the face-mask motif excavated in Nanjing have been dated to 229-280 (東吳期 Eastern Wu period), or Ezhou 鄂州 before the construction of the citadel of Nanjing. Yamagata Mariko divided the stratigraphy at the Hoan Chau in the Tra Kieu Citadel into three periods, and she concluded that the face-mask tile end that was unearthed from the uppermost layer derived from the motif found in the citadel of Nanjing and was to be dated to the third century. ${ }^{12}$ But this theory of the spread of the motif from China has yet to be substantiated.

Period Roof Tile Excavated in Vietnam" [Japanese], in Transformation of Silk Road, China (Tokyo: Yuzankaku, 2007), 227-254.

12 Yamagata, "Formation of Lin Yi," 167-184; Yamagata and Momoki, "Han and Six Dynasty," 227-254; Yamagata Mariko and Nguyen Kim Dung, "Ancient Roof Tiles Found in Central Vietnam," in 50 Years of Archeaology in Southeast Asia: Essays in Honour of Ian Glover, ed. B. Bellina, E. A. Bacus, T. O. Pryce, and J. W. Christie (Bangkok: River Books, 2010), 194-205. 


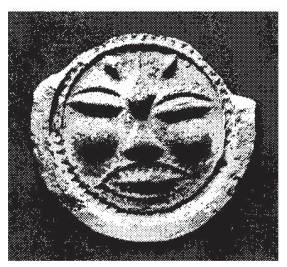

1

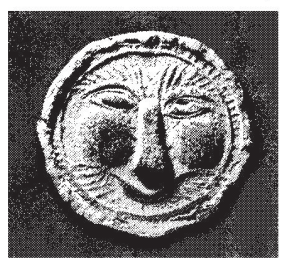

2

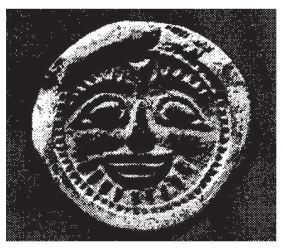

3
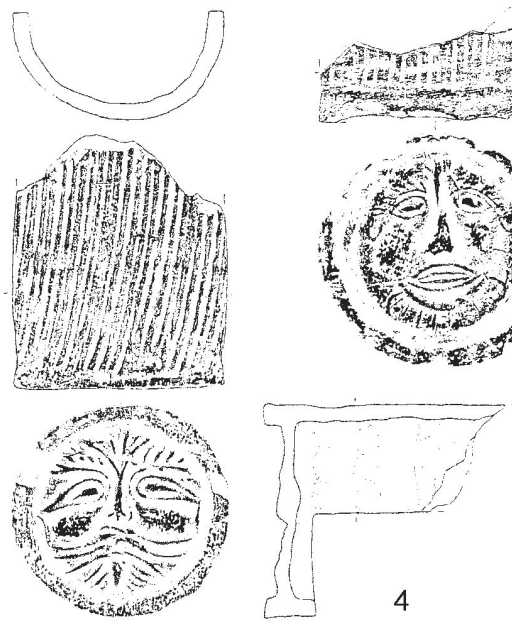

운

ㅇ. $10 \mathrm{~cm}$

FIGURE 6 Face-mask tile ends of Nanjing (1-3) and Tra Kieu (4-5). ${ }^{13}$

In the case of the Lung Khe Citadel, the tile end was unearthed in L4-1, which is one layer above the lowest layer. That layer was dated to the fourth quarter of the second century by Dr. Nishimura. ${ }^{14}$ Thus the oldest face-mask tile end unearthed to date comes from the Lung Khe Citadel. That may indicate the spread of the motif from northern Vietnam to Tra Kieu. However, the tile ends unearthed in Nanjing did not display the motif from the Lung Khe Citadel. So a typological gap exists between the sites. Some typological distance between Tra Kieu and Lung Khe also exists, but it is not as great as that between Nanjing and Lung Khe. However, the date is still not clear because the date of the tile end was not based on comparative stratigraphic studies with the artifacts excavated in Nanjing.

In the second and third centuries, roof tile ends with lotus or human face motifs were popular, and from the fourth century onward, the most popular roof-tile end motif was the lotus petal motif found at LK1.

\footnotetext{
13 Yamagata, "Formation of Lin Yi," 167-184; Yamagata and Momoki, "Han and Six Dynasty," 227-254.

14 Nishimura, "Basic Data and Recognition," 57-101.
} 
The roof-tile end with lotus petal motif appeared as early as the Qin Dynasty, but it did not continue to be used after that period. At the moment, the rooftile end with the lotus petal motif from the Lung Khe Citadel is the oldest in South China and in northern and central Vietnam. Dr. Nishimura thought that the prosperity of the Lung Khe Citadel was related to the prosperity of Buddhism. During the administration of Si Nhiep, wealth derived from commerce in the South China Sea. San Kuo Chih records that when Si Nhiep visited, the Sogd people (胡人) stood in line and burned incense. The Dau temple, which is located south of the Lung Khe Citadel, was the place where Buddhism was first introduced. A legend (古珠録) written in the second half of the fourteenth century ${ }^{15}$ recorded that during the Si Nhiep rule, Indian Buddhists lived in the Dau Temple. ${ }^{16}$

After Si Nhiep, Giao Chi during the Southern-Northern Dynasty (420-589) remained the center of Buddhism, and historical studies of Giao Chi District show that Buddhism was popular at that time. ${ }^{17}$ The roof-tile ends with lotus petal motifs were then the major type found in the capital of Lung Khe Citadel, Long Bien, which points to a close relationship between Buddhism and Giao Chi District at that time.

If Dr. Nishimura's hypothesis is correct, the fact that the major motif appearing on roof-tile ends from the Tra Kieu Citadel during the third century is the human face rather than the lotus petal may indicate a connection with a religion other than Buddhism (or Hinduism), ${ }^{18}$ or a relationship between Hinduism and Buddhism. It is also possible that the human face motif may have originated with an Indian mask maker. ${ }^{19}$

If the lotus motif indicates a relation with Buddhism, then Buddhism did not infiltrate the Tra Kieu Citadel as deeply as it did the Lung Khe Citadel. Of course, the roof-tile-end motif alone does not prove a connection with Buddhism, but it can be seen as evidence of cultural exchange.

15 Nguyen Quan Hong, Divan chua Dau (Record of the Dau Temple) (Hanoi: Social Science Publisher, 1997).

16 Nishimura Masanari, "Nhan xet moi ve nien dai cuoi cung thanh Luy Lau Lung Khe, (h. Thuyan Thanh, tinh Bac ninh)" (New Understanding of Luy Lau, Lung Khe Citadel, Thuan Thanh, Bac Ninh Province), Nhung phat hien moi ve Khao Co Hoc nam 2000 (New Discoveries in Archaeology in 2000) (2001): 629-632.

17 For example, Le Manh That, Lich su phat giao Viet Nam Tap 1 (History of Vietnamese Buddhism, vol. 1) (Hue: Thuan Hoa Hue Publisher, 1999).

18 Nishimura, "Basic Data and Recognition," 57-101.

19 Trần Quoc Vuong and Hoang Van Khoan, "Dau ngoai Tra Kieu Quang Nam Da Nang” (Roof Tile of Tra Kieu, Quang Nam Da nang), Nhung Phat Hien moi ve Khao Co Hoc 1985 (New Discoveries in Archaeology in 1985) (1986): 235-237. 


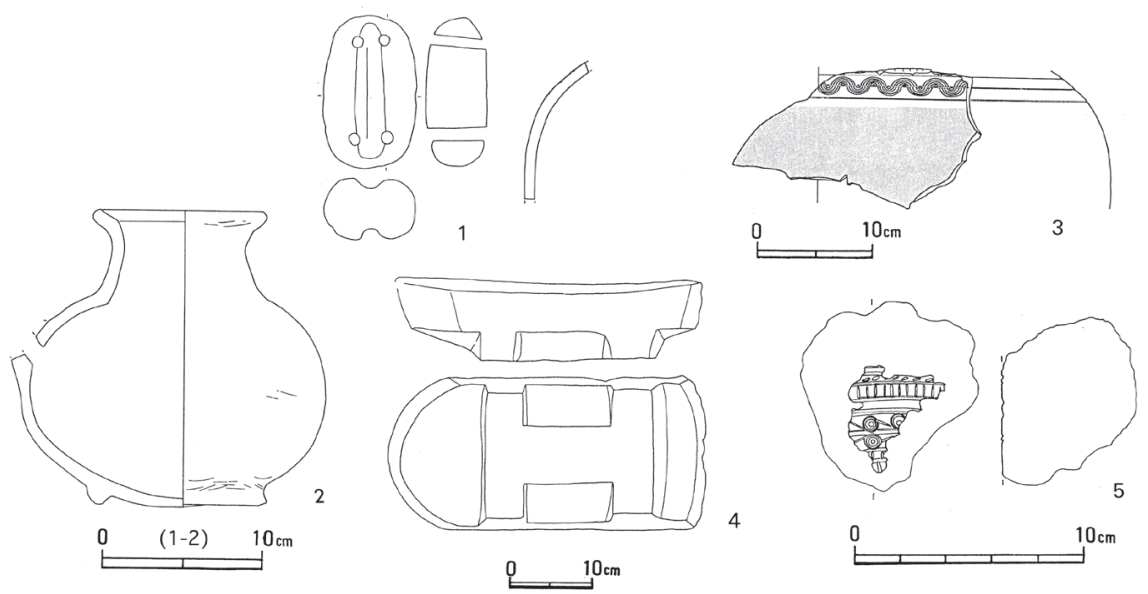

FIGURE 7 Artifacts of rare type unearthed in the Lung Khe Citadel.

Figure 7.1 shows a net sinker. The same type of net sinker was unearthed at the Tam Tho, ${ }^{20}$ Tra Kieu, and $\mathrm{Oc} \mathrm{Eo}^{21}$ sites. Typologically, it was originally from China. It is interesting to see the similarities among these daily tools, perhaps a result of river transportation. Figure 7.2 is a kendi that originated from India and was unearthed when digging clay to make bricks in the Lung Khe Citadel. A similar kendi in the Bac Ninh Museum (Fig. 8) probably came from a Han grave. The Chinese characters were written on the bottom of the kendi before it was put into the kiln.

Kendi have been unearthed over a wide area in Southeast Asia. Typologically, these kendi are similar to the one from Tra Kieu, ${ }^{22}$ but artifacts of similar shape are found not only in the Oc Eo Culture. ${ }^{23}$ They are spread over a wide area of Southeast Asia, including Thailand and the Malay Peninsula. When identifying the typological transmission of objects from one region to another within Southeast Asia, ${ }^{24}$ it is important not only to discuss the pattern of the direction of the transmission but also to examine how the transmission was accepted and how the distinctive characteristics were formed in each region as a whole.

\footnotetext{
20 Janse, Archaeological Research in Indo-China, vol. 1.

21 Nishimura, "Basic Data and Recognition," 57-101.

22 Yamagata Mariko, "Sites of Nation Formation Period in Middle Vietnam," Kikankoukogaku 66 (1999): 66-70.

23 Le Xuan Diem, Dao Linh Con, and Vo Si Khai, Van hoa Oc Eo, nhung kham pha moi (New Research of the Oc Eo Culture) (Hanoi: Social Science Publisher, 1995).

24 For example, Yamagata, "Formation of Lin Yi," 174.
} 


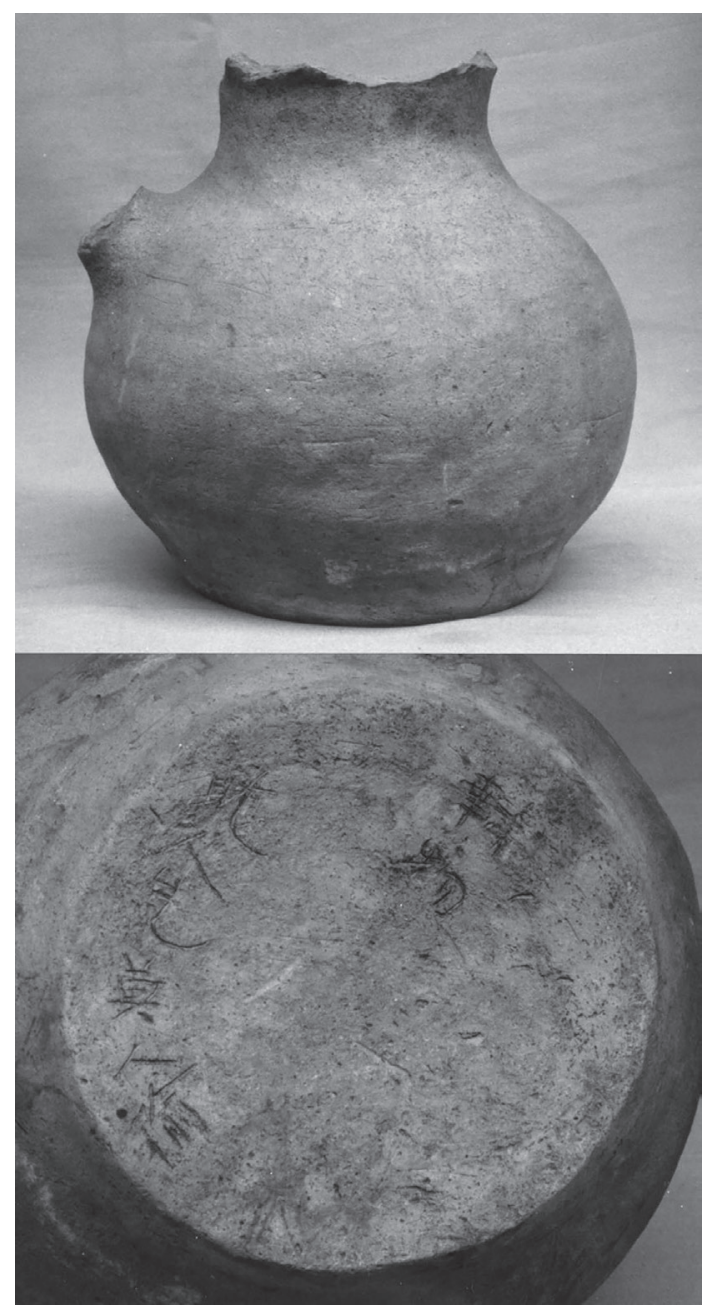

FIGURE 8

Kendi unearthed in Bac Ninh Province.

As far as kendi are concerned, in the north, a pot shaped like an elephant's head with a trunk has attracted attention. The trunk part was likely influenced by kendi. Thus, this type of pot did not clearly come from China. ${ }^{25}$ This pot also has the circle motif that is often used on bricks and bronze drums. This type of artifact is rarely seen and displays Chinese, Northern Vietnamese, and Southeast Asian elements. It was excavated from a Ghi Ve Han gravesite (мв) located about $10 \mathrm{~km}$ north of the Lung Khe Citadel, and dates from the

25 Mikami Tsuguo, Ceramic Art of the World, vol. 16, Southeast Asia (Tokyo: Shougakukan, 1984), 10. 
latter half of the second century to the early third century CE. ${ }^{26}$ Similar artifacts were excavated at the Lach Truong site, Thanh Hoa Province, and dated to the second century CE. ${ }^{27} \mathrm{~A}$ number of kendi were unearthed in the Oc Eo Culture in southern Vietnam, and they originated from India. Both human face tiles and kendi are used in religious contexts, though the major religion practiced in Tra Kieu may have been different from Buddhism or other religions.

Figure 7.3 shows a shard of an earthenware vessel bearing a motif of connected semicircles that was probably drawn with a compass. The body is soft and grainy and pale white-colored and is quite different from any other earthenware or pottery. It has been confirmed that this semicircular motif exists only in the Oc Eo Culture. ${ }^{28}$ The shard can be dated to the second century CE because it was unearthed near the lowest layer of $\mathrm{LK}_{3}$.

Figure 7.4 depicts the stone dish with legs that was unearthed when digging clay to make bricks in the Lung Khe Citadel. Stone dishes and pestles were also unearthed in continental Southeast Asia, the Malay Peninsula, and Indonesia, and were originally from India. None have yet been discovered in Northern Vietnam. A stone dish with legs was unearthed at the Tra Kieu and Oc Eo sites in the Mekong Delta. ${ }^{29}$ The stone dish in Figure 7.4 is not different from those unearthed in the south and middle of Vietnam. The artifact was brought to the Lung Khe Citadel from that area and might have been used by a person influenced by Indian culture. At a later stage, the legs became higher, and thus Figure 7.4 shows a very early tile. A stone dish was also unearthed at the Nhon Nghia site in Can Tho Province and dated to the fourth to sixth century. ${ }^{30}$ The dish shown in Figure 7.4 is older than the one from Nhon Nghia and probably dates from the second to third century CE.

Figure 7.5 shows the two sherds from the bronze drum mold. The first one (Fig. 9) was found in clayish sediments disturbed by modern development near

\footnotetext{
26 Nishimura, "Basic Data and Recognition," 57-101.

27 Janse, Archaeological Research in Indo-China, vol. 1.

28 Louis Malleret, L'archéologie du Delta du Mékong, vol. 2 (Paris: École française d'ExtrêmeOrient, 1960).

29 Ibid.

$30 \quad$ Nguyen Duy Ty and Nguyen Phuong Anh, Nhung hien vat Van hoa Oc Eo o bao tang tinh Can Tho (Artifacts of the Oc Eo Culture in Can Tho Province) (Can Tho: Can Tho Museum, 1995); Nishimura Masanari, Nguyen Duy Ty, and Nguyen Xuan Ly, The Excavation of Da Kai: A Neolithic Circular Setttlement Site in the upper Reach of the Dong Nai River, Southern Vietnam (Shimonoseki: Foundation to Safeguard the Underground Cultural Heritage in Southeast Asia, 2008).
} 


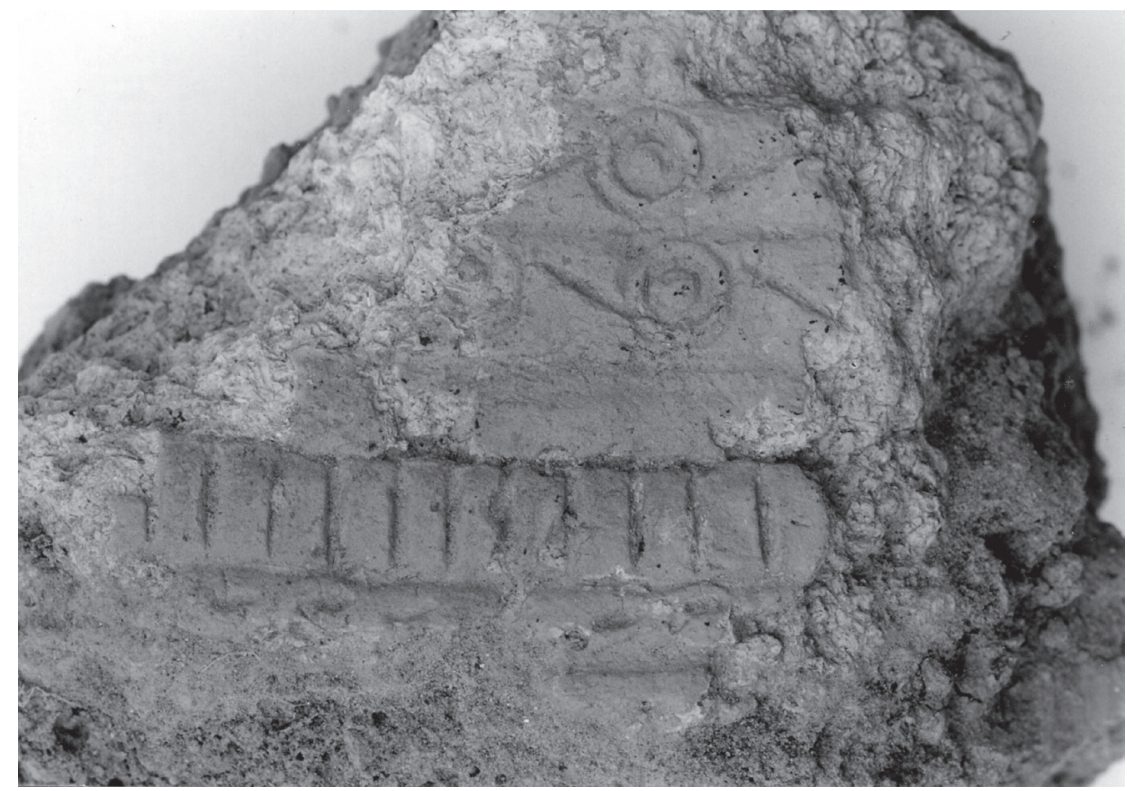

FIGURE 9 Fragment of mold of bronze drum found at the Lung Khe Citadel in 1988 by Dr. Nishimura.

the LK2 point in the Lung Khe Citadel. ${ }^{31}$ The second one (Fig. 10) was excavated in Layer $8 \mathrm{c}$ of $\mathrm{LK}_{5}$. The second sherd also has a connected round motif like the first one, so both are of the same date. Layer 8 belongs to the upper layer of the second stage of construction work, so the bronze drum mold can be dated to the second century CE. The casting of a bronze drum, important in the local culture, took place at the very center of Han political power, which indicates that the Chinese authorities understood the importance of the bronze drum.

\section{Lung Khe Citadel: The Age of Commerce in the Second and Third Century CE}

The excavations at the Lung Khe Citadel (Long Bien) suggest that the second and third century CE was an age of commerce. The Lung Khe citadel and the

$31 \quad$ Nishimura Masanari, "Khuon duc trong dong duoc phat hien trong long thanh co Luy Lau" (Discovery of Bronze Drum Mold in Luy Lau Citadel), Khao Co Hoc (Archaeology) 1998, no. 4 (1998): 99-100. 


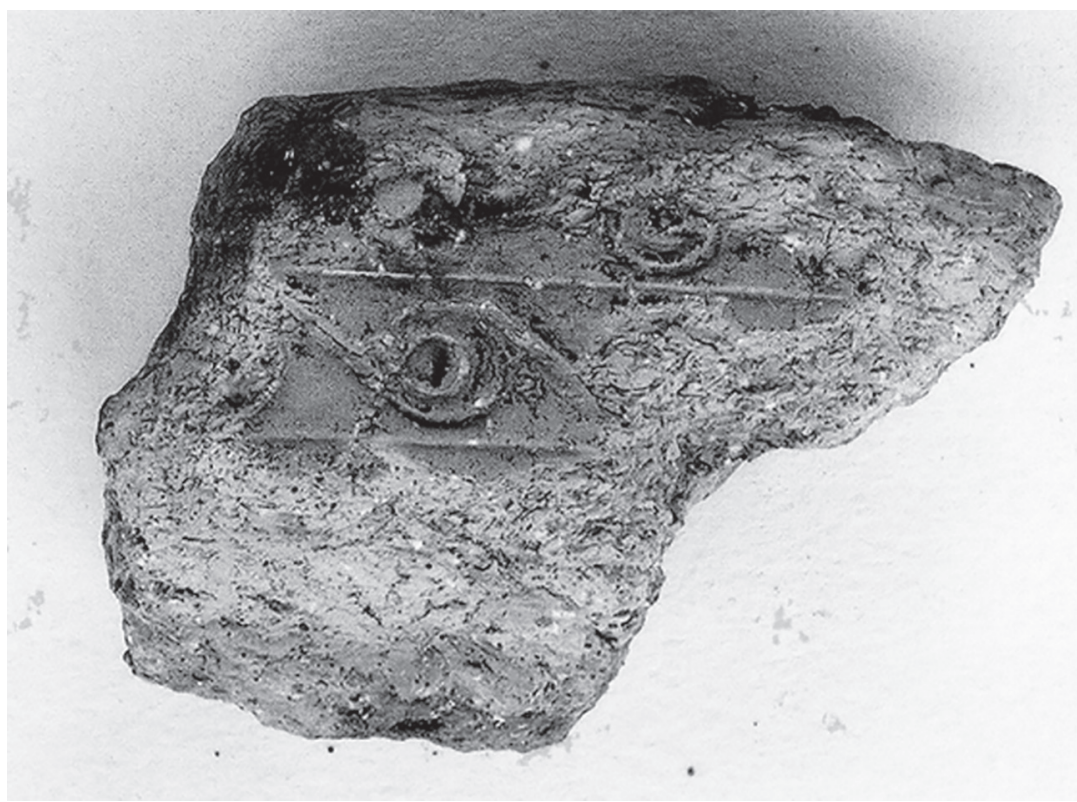

FIGURE 10 Fragment of mold of bronze drum excavated in L8c at the Northern Mound LK5 Site.

surrounding area yielded face-mask roof-tile ends and stone dishes influenced by India, as well as kendi and earthenware probably originally from the Oc Eo Culture, most of which could be dated to the second or third century. Dr. Nishimura proposed that this area was a center of Buddhism in the second century, based on the continuing development of the roof-tile ends bearing the lotus-panel motif and the legend that Buddhism was first introduced at the Dau Temple.

The casting of the bronze drum in the Lung Khe Citadel must have served a political purpose of the Chinese ruler (for example, to win over the local people), but there was still a succession of local culture, as it was a very creolized cultural space. Giao Chi District in the second to early third century was a very unique place where cultural exchange was encouraged by its geopolitical position, the international situation, and the chaos in China. ${ }^{32}$ The hybrid culture or religion there could have enticed the Eastern $\mathrm{Wu}$ (吳) to formulate a policy of advancing south or taking action against the south.

32 S. O'Harrow, "Men of Hu, Men of Han, Men of the Hundred Man: The Biography of Si Nhiep and the Conceptualization of Early Vietnamese Society," Bulletin de l'Ecole française d'Extrême-Orient Année 75, no. 1 (1986): 249-266. 
The far-reaching hypothesis raised by Dr. Nishimura suggests that Buddhism in Jianye (建業, namely, Nanjing 南京), represented by the roof-tile ends bearing face-mask or lotus-petal motifs, could have come from the Lung Khe area. ${ }^{33}$ Further studies are much needed to test this theory.

33 For details, see Nishimura, Archaeology and Ancient History of Vietnam. 